\title{
Morro, logo existo: a morte como acontecimento jornalístico
}

\section{I die, therefore I am: death as a journalistic happening}

\section{Milena Carvalho Bezerra Freire de Oliveira-Cruz}

\section{Resumo}

Considerando as significações da cultura presentes no interior das práticas sociais cotidianas e a comunicação como espaço privilegiado para esta observação, este artigo se propõe a traçar um caminho que percorre as diversas elaborações da morte como elemento expressivo na constituição do humano e do social, cujos sentidos se formulam, explicitam e circulam na enunciação das narrativas jornalísticas. Para reconhecer as tramas que compõem estas relações, faz-se necessário observar a concepção do homem como ser de cultura e ciente de sua finitude, bem como entender as relações e conseqüências desta consciência em sua organização social e orientação individual. A partir destas considerações, então, o artigo busca observar a participação da comunicação como instância que elabora, inscreve e reorganiza sentidos fundamentais para a construção da vida social.

Palauras-chave:

Jornalismo, Morte, Processos sociais

\section{Abstract}

Considering the different cultural meanings within everyday social practices and communication as a privilege medium for this observation, this article intends to explore the several implications of death as an expressive element in the constitution of the humane and the social, whose meanings are embedded and expressed in the enunciation of the journalistic narrative. In order to recognize the threads that compose those relation, it's necessary to observe the Human conception as a cultural being, aware ofits finite life to recognize the elements that form these relations. Furthermore, to understand the implications of this awareness in the social organization and the individual orientation. This article proposes to observe the role which communication plays as medium that elaborates, inscribe and reorder fundamental meanings to build social life.

Key words:

Journalism, Death, Social process 


\section{Cultura, morte e sujeito}

Da intersecção entre morte e cultura desencadeiam duas premissas nada novas, mas não por isso menos importantes para pensar o homem: a elaboração do conceito de cultura como um elemento indissociável do humano e a certeza de ser este o único ser consciente de sua finitude. Para isto, é válido recorrer a Clifford Geertz (1989: 3233) que, para lançar a idéia do que seria o homem, propõe pensar a cultura como um conjunto de mecanismos de controle (planos, receitas, regras, instituições) dos quais o ser humano é "desesperadamente dependente". Esta noção desenvolve-se a partir do pressuposto que o pensamento é social e público, e, assim sendo, palco de construção e partilhamento de signos da experiência humana (individual e coletiva).

$\mathrm{Na}$ maior parte dos casos, estes signos se apresentam ao indivíduo como dados, já circulantes na comunidade. E, embora possam sofrer adições, subtrações e alterações, são coletivos e independentes da forma de apropriação que o sujeito faz deles - espontânea, deliberada ou cautelosa. O que importa, de fato, é que tais signos, organizados em padrões de cultura, são utilizados pelos sujeitos sempre com o mesmo propósito: autoorientar-se no curso das suas experiências individuais e coletivas (Geertz, 1989: 33).

Percorrendo as tramas da constituição do homem como ser de cultura, de significações, temos contato com o que representa a apreensão simbólica de sua condição transitória. O "saber" da morte, a impossibilidade de negar racionalmente a própria finitude, colabora decisivamente na significação que o homem fará da vida, e, portanto, de si, da sociedade e do mundo. Neste sentido “(...) podemos afirmar que a humanidade

Percorrendo
as tramas da
constituição do
homem como
ser de cultura,
de significações,
temos contato com
o que representa
a apreensão
simbólica de
sua condição
transitória

Estudos em Jornalismo e Mídia Ano V № 1 - 10 semestre de 2008 não alcança a consciência de si mesma a não ser através do enfrentamento da morte" (Dastur, 2002: 13).

Para Edgar Morin (1997: 10-11), aliás, a sociedade só se institui como organização por, com e na morte, uma vez que a reprodução dos sistemas simbólicos que compõem a cultura só tem sentido pleno em função da morte. A consciência da morte é tida como motor que orienta a necessidade de transmissão e partilhamento dos signos que compõem a cultura para mantê-los existentes. Desta forma, a certeza da finitude também estimula a elaboração de uma série de representações que orientam atitudes e comportamentos humanos - especialmente expressos em ritos e manifestações que configuram a organização do tempo (finito) a ser vivido. Aqui é importante esclarecer que não se tratam de atitudes que se norteiam perante a morte em si. Como componente intrínseco da cultura, o que orienta a conduta humana nestes casos são as representações sobre a morte que se articulam, se classificam e assumem função conforme cada sistema simbólico e em cada sociedade de uma maneira mais específica.

As representações da morte vêm se modificando ao longo dos tempos, sendo possível observar verdadeiras transformações no que diz respeito às sensibilidades humanas frente à própria finitude. Seguindo a demarcação proposta por Ariès (2003), dois momentos têm reflexos que se apresentam na significação da finitude, hoje: a morte do outro e a morte interditada. A partir do século XVIII, com uma maior integração social, a dramaticidade da morte voltou-se para a partida do próximo. A individualização do morto passa a variar de acordo com a proximidade de quem fica: “(...) quanto mais o 
${ }^{1}$ Esta idéia de "a"mortal dá conta da representação que considera $a$ inexistência da morte; o que se difere de ser "imune" a ela - que pressupõe a existência da morte para que se possa ser imortal. morto for próximo, íntimo, familiar, amado ou respeitado, isto é, 'único', mais violenta é a dor; nenhuma ou quase nenhuma perturbação se morre um ser anônimo, que não era 'insubstituível”' (Morin, 1997: 32).

Entre os séculos XVIII e XIX, vê-se a higienização da morte e a medicalização do doente. A possibilidade de prolongar a vida causa o horror à morte e este movimento consolida-se até a sua interdição na sociedade ocidental. A própria maneira de morrer também sofreu alterações: hoje o indivíduo morre no hospital, e não mais em casa, e a família, por sua vez, acompanha o processo cada vez mais de longe.

\section{A morte como acontecimento}

Quanto mais o indivíduo tenta se colocar alheio ao enfrentamento da morte, mais o assunto torna-se repulsivo, porém, inevitável, por ser condição da existência humana. Diante disso, a saída encontrada pela sociedade atual - que pode adiar, suavizar, mas não contestar a morte - é exorcizá-la do cotidiano como se ela não existisse, modificando a experiência sobre o tempo vivido na contemporaneidade:

[...] são as descobertas extraordinárias da tecnologia médica e da pesquisa biológica nas duas últimas décadas que fornecem material para a mais antiga aspiração humana: viver como se a morte não existisse, apesar de ser nossa única certeza. Com isso, realiza-se a subversão final do ciclo de vida, e a vida torna-se esta paisagem monótona entrecortada por selecionados momentos de experiências ricas e pobres na eterna butique dos sentimentos personalizados (Castells, 1999: 478).

Esta sensação de amortalidade ${ }^{1}$, vivida na fragilidade de um cotidiano que se sugere atemporal é também conseqüência do escamoteamento da finitude humana na atualidade. O tempo, aliás, é outro fruto de modificações sensíveis. A contradição se põe na exigência de aproveitamento qualitativo e inesgotável do tempo em todas as esferas da vida social com base em uma perspectiva única: que o destino do indivíduo depende de suas realizações e ações em vida. Mas, pergunto: que destino? Se (...) "vivemos sobre o futuro: 'amanhã', 'mais tarde', 'quando tivermos uma boa situação', 'com a idade hás-de compreender'. Estas inconseqüências são admiráveis, porque enfim, trata-se de morrer" (Camus ,s/d: 25).

Assim, projetamos nossas vontades para o tempo futuro, como se ele nos pertencesse unicamente. A morte, de tão esquecida, ou escondida, aparece no cotidiano abruptamente. E, mesmo sendo a única certeza, é recebida como surpresa, como evento inesperado.

A sociedade ocidental insiste no caráter acidental da morte: acidentes, doenças, infecções, velhice adiantada. A morte fica despojada do caráter de necessidade em termos do processo vital. É sempre um assombro. O traumatismo provocado pela morte é sempre uma irrupção do real. No inconsciente estamos todos persuadidos da nossa imortalidade, sem registro da morte, como o animal cego (Kovács, 1992: 39).

Embora não seja possível negar a existência da morte, o seu caráter acidental como noção de falha do curso normal remonta a construção de uma rotina que se baseia na desejada amortalidade. Esta significação da morte como irrupção do real, 
como evento inesperado, em muito se assemelha ao conceito de acontecimento desenvolvido por Adriano Duarte Rodrigues (1993: p. 27) como sendo "tudo aquilo que irrompe a superfície lisa da história de entre uma multiplicidade aleatória de fatos virtuais", destacando-se quanto mais imprevisível for sua realização. Esta "imprevisibilidade" da morte, é claro, só pode aproximar-se da idéia de acontecimento se considerada como elemento distante da elaboração do cotidiano.

A existência humana constrói-se, desta maneira, a partir de uma presença "vigilante" da morte - que pode romper o cotidiano inesperadamente. Esta idéia de temporalidade restrita e urgente colabora com a noção de efemeridade da vida, sentida e absorvida como período único de realizações. Contudo, este mesmo sentimento, que apresenta muitas vezes apenas o lado positivo desta urgência (carpe diem!), lembra ao sujeito, mesmo que de maneira latente, o seu fim intransponível. Esta linha tênue que equilibra o homem entre noções de vida e morte, normalmente, se desdobra na atribuição de "sentidos" para a vida e para várias ações que nela se projetam.

A morte aparece, portanto, como representação da cultura que apresenta noções da regulação social necessária para organizar as projeções destes "sentidos de vida" individuais - de sujeitos finitos inscritos num coletivo de tempo contínuo (que permanece após sua partida). A participação deste sujeito no social se dá na interiorização dos signos, papéis e padrões, que variam conforme a experiência, mas que são partilhados e conhecidos por todos - o que torna o mundo subjetivamente real para o sujeito. (Berger e Luckmann, 1985: 103). Considerando a compreensão da natureza comunicativa

\section{A imprevisibilidade da morte só pode aproximar-se da idéia de acontecimento se considerada como elemento distante da elaboração do cotidiano}

da cultura, percebe-se o fundamental papel da comunicação no processo que produz e faz circular estas significações que se desdobram da certeza da morte e auxiliam a constituir os indivíduos (não só decodificadores, mas produtores destes sentidos). Isso, por sua vez, também contribui com as sustentações desta própria coletividade e o seu sentido de realidade.

\section{Morte, acontecimento $e$ a realidade percebida}

Interessa notar a morte como elemento que nos permite discernir a construção do significado moral dos acontecimentos em vida: “(...) o que seria negado a um indivíduo sem horizontes finitos. O 'chamado da consciência' que a consciência da finitude traz, estimula os homens a perceberem sua "essência temporal como seres-para-amorte" (Giddens, 2002: 52). É através da existência limitada, portanto, que o homem moderno pauta seus objetivos, constrói seu cotidiano e atribui sentidos às suas relações e conquistas. Sem o fim previsto, dificilmente as expectativas e os acontecimentos vividos seriam iguais, ou, mesmo sendo, teriam as mesmas significações que as construídas pelo homem consciente de sua morte. Estas construções simbólicas "por extensão" de outros acontecimentos a partir do "chamado da consciência" provocado pela finitude são refletidas por Adriano Duarte Rodrigues:

O nascimento e a morte são por isso os aciden tes-limite em relação aos quais todas as outras ocorrências se posicionam e se referem. Para o nascimento e para a morte não há explicação plausível porque não há sentido racional que os compreenda numa lógica causal, num antes e num depois. Por isso, a notícia é no 
mundo moderno o lado negativo da racionalidade, no sentido fotográfico deste termo. O racional é da ordem do previsível, da sucessão monótona das causas, regida por regularidades e por leis; o acontecimento é imprevisível; irrompe acidentalmente à superfície epidérmica dos corpos como reflexo inesperado, como efeito sem causa, como puro atributo (Rodrigues, 1993: 129).

Volto ao homem como produto e produtor de representações que se constroem, se organizam e se tornam significantes quando reproduzidas, circulantes, partilhadas e, por isso, coletivas. Este movimento próprio da cultura perpassa o sujeito e a sociedade de modo que sua existência aponta esta operação interdependente de construção, de um reconhecimento mútuo e contínuo que exprime o individual no coletivo e vice-versa. Como fruto deste sistema, os acontecimentos, por sua vez, auxiliam na elaboração da regularidade, da padronização (a superfície lisa), bem como do seu oposto (a irrupção), criando parâmetros para o esperado, o possível, e, por fim, o real.

Nesta construção do real, os acontecimentos se apresentam como referências para uma elaboração espacial e temporal que ordenam a noção de passado e futuro, sendo estes construídos e reconstruídos nas atividades socialmente organizadas pelas rotinas. As construções que derivam dos acontecimentos, portanto, são base para a formulação de recursos que dividem, demarcam e moldam a vida em sociedade (Molotoch e Lester, 1993: 35). Diante de uma previsível multiplicidade de acontecimentos co-existentes nestas elaborações, Marilyn Lester e Harvey Molotch dividem os fatos sociais entre ocorrências suplementares e

e importantes, sendo importantes aquelas que são úteis na demarcação do tempo, e por isso, disponíveis para sua materialização como acontecimento.

Para eles, a existência de demarcações temporais criadas e partilhadas na esfera social dá suporte ao interessante conceito de tempo público como dimensão da vida coletiva em que se protagonizam acontecimentos públicos, orientados a partir de um passado padronizado e perceptualmente partilhado, presente e futuro. O sentido deste tempo público, portanto, se dá na produção e assimilação destes acontecimentos públicos, existentes como significação a partir do discurso que circula e se legitima nos assuntos públicos:

Assim, o conteúdo das concepções de um indivíduo da história e do futuro da sua comunidade vem a depender dos processos através dos quais os acontecimentos públicos se transformam em recursos do discurso nos assuntos públicos. O trabalho dos historiadores, jornalistas, sociólogos e analistas políticos ajuda a realizar esta tarefa de vários públicos, oferecendo aos cidadãos um leque de ocorrências a partir das quais se elabora um sentido do tempo público (Molotoch e Lester, 1993: 36).

O papel do jornalismo configura-se como relevante não só na interpretação como na própria construção do sentido desta realidade percebida
Desta maneira, é na esfera do tempo público que se balizam parâmetros de mobilidade e comportamentos a partir da elaboração de real que constrói, interpreta e faz circular representações contidas nos acontecimentos públicos. O papel do jornalismo como estrutura mediadora que realça ocorrências ao plano dos acontecimentos públicos no discurso social configura-se como relevante não só na interpretação como na própria construção do sentido desta realidade percebida. 


\section{A morte como acontecimento jornalístico}

Ao retomar a morte como "acidente-limite" que orienta a significação e posicionamento de outros acontecimentos também reguladores da experiência individual e coletiva, impera-se perceber que este papel norteador da morte se dá ainda pelo silêncio que marca seu interdito, ou pela transformação de seu caráter irrevogável em "inesperado". Em função disso, o discurso jornalístico sobre a morte se apropria de representações que vão classificá-la num parâmetro de normalidade e expectativa, em que, quanto mais insólita ou inesperada, a morte estará mais próxima da classificação como acontecimento jornalístico.

A significação do caráter "inesperado" da morte aproxima-se da elaboração do acontecimento a partir da sua forma (subentendendo que, embora inexorável, existam maneiras mais, ou menos, "normais", "regulares", ou momentos mais "adequados" para se morrer). Diante de uma possibilidade de prolongamento da expectativa de vida, a morte repentina é aquela que causa espanto. Para Freud (1996: 300), a sensibilização causada pela morte concentra-se no pensamento sobre a sua "causa", o que revela a sua consideração como um "fato" e não como algo natural. Vê-se claramente a construção de uma representação para a morte - não se trata da morte em si, mas de sua relação enquanto fato, e, portanto, acontecimento.

Desta maneira, a adequação do momento para a realização deste "evento" diz respeito às realizações do indivíduo no que concerne às suas expectativas individuais e ao seu papel social: "o modo como uma pessoa morre depende em boa medida de que ela tenha sido capaz de formular objetivos e alcançá-los, de

\section{Quanto mais insólita ou inesperada, a morte estará mais próxima da classificação como acontecimento jornalístico}

imaginar tarefas e realizá-las. Depende do quanto a pessoa sente que sua vida foi realizada e significativa - ou frustrada e sem sentido" (Elias, 2003: 72). Estas representações que auxiliam na constituição de um "sentido" para a morte do outro, tornando possível inferir variações do quanto inesperado pode ser o fato, colaboram para identificação da noticiabilidade, e, portanto, da construção da morte como acontecimento jornalístico.

Dois aspectos são relevantes para a apreensão desta morte insólita como apropriação e construção no acontecimento jornalístico. O primeiro diz respeito a constatação de que todo acontecimento quando mediado, ou seja, quando representado simbolicamente pela linguagem, se transforma no relato do acontecimento, que, por sua vez, não será mera locução, mas um novo acontecimento a integrar o mundo: o chamado ato ilocutório (Rodrigues, 1993: 31). O ato ilucutório, como construção do acontecimento na enunciação, dá nova perspectiva ao fato observado através da formulação, adequação e subjetividades do enunciador e da relação de reciprocidade dos interlocutores.

A constituição do jornalista como sujeito competente para a enunciação produz no relato que este faz do acontecimento um novo estado de significação para o próprio fato, existente na própria enunciação, ou pelo fato de ser enunciado - permitindo ao discurso jornalístico contribuir na construção deste "estado das coisas", que orientam a realidade percebida socialmente: "Ao darem conta dos actos enunciativos, os media não só lhes conferem notoriedade pública, alargando (...) o âmbito e o alcance das transformações que operam o mundo, como realizam igualmente novos atos ilocutórios e 
e perlocutórios de acordo com as suas próprias regras enunciativas" (Rodrigues, 1993: 31).

Interessa notar que tais significações colocam a finitude humana como elemento tanto "presente" subjetivamente na orientação do comportamento e da percepção da normalidade social, quanto fenômeno "ausente" objetivamente do cotidiano próximo, quando revela seu caráter inesperado ao irromper na superfície da rotina. Além disso, o relato da morte, talvez de forma mais especial que qualquer outra ocorrência resignificada pela enunciação, revela a construção de um dado que só existe como representação - sendo talvez o único fato que, definitivamente, o enunciador não conhece, pois não há experiência da morte:

Chego finalmente à morte e ao sentimento que dela possuímos. Sobre isso, tudo foi dito e é uma questão de decência se evitar o patético. Nunca, porém, nos espantaremos suficientemente com o facto de toda a gente viver como se "ninguém soubesse". É que, na realidade, não há experiência da morte. No sentido próprio, só aquilo que foi vivido e tornado consciente, foi experimentado. Mal é possível falar-se da experiência da morte dos outros. É um sucedâneo, uma visão do espírito, e nunca ficamos muito convencidos. (Camus, s/d: 27).

\section{A re-significação do sujeito pela enunciação}

A morte como acontecimento jornalístico será sempre uma representação que se constrói essencialmente no outro, na experiência do outro. Contudo, é na ruptura que a ausência do outro provoca no cotidiano dos sobreviventes que se elaboram as significações "por extensão" ao acontecimento da morte. Estas significações dão conta daquilo que se esconde, se nega, porque se teme. A morte do "outro" evidencia a fragilidade de "si", inevitavelmente consciente da condição de "ser-para-a-morte".

Se o discurso que constrói o acontecimento jornalístico, desta feita, elabora um novo acontecimento pela enunciação, entendo que a morte expressa neste discurso (que já não se significa no evento em si, mas na sua representação enquanto fato social) também não se refere ao sujeito morto, mas sim evidencia a construção de um outro sujeito re-significado - primeiramente por sua morte, e posteriormente pela enunciação de sua morte. Falo, portanto, que a morte apropriada pela enunciação no discurso jornalístico constrói no falecido um outro sujeito que não aquele que deixou de viver, mas um sujeito que interpela o sobrevivente na sua condição de "desinteressado" quanto ao seu próprio fim; um indivíduo que carrega em sua morte as representações valorativas quanto aos "sentidos" da vida, além de remeter à significação que o coletivo confere aos seus membros conforme seus papéis e participações.

A partir de um levantamento de estudos já realizados sobre a representação midiática da morte, alguns aspectos se mostram importantes para que a ocorrência do fato seja relevada à condição de acontecimento jornalístico: a circunstância do falecimento, o papel e a participação social do falecido, e, por fim, uma reivindicação do poder na sociedade. Partindo destas reflexões, Marialva Barbosa (2004) faz uma interessante análise da morte midiática, identificando construções discursivas que variam da dramatização à indiferença, conforme mudam os personagens e as circunstâncias. 
Na sua análise (Barbosa, 2004: 2), a morte de caracterização dramática e excessiva é elaborada no discurso midiático quando os falecidos são personalidades públicas, cujos cortejos de despedida são ritos públicos emocionados, acompanhados pela população nas ruas ou pela transmissão televisiva. Para Freud (1996: p. 300), o sentimento de perda se intensifica de acordo com a relação entre sobreviventes e falecido: "o complemento a essa atitude cultural e convencional para com a morte é proporcionado por nosso completo colapso quando a morte abate alguém que amamos".

Nestas narrativas midiáticas, não existe, contudo, espaço para a exibição do corpo - a representação da morte se constrói na dramatização, na celebração. $\mathrm{O}$ sujeito, neste contexto, também é re-significado pela sua morte, uma vez que a dramaticidade da partida é ampliada pela enunciação midiática. Mesmo quando o falecido de conhecimento público tem uma história de contradições ou polêmicas, costuma-se retirar do discurso quaisquer desavenças após a sua morte. "Deixamos de criticá-la, negligenciamos suas possíveis más ações (...), e julgamos justificável realçar tudo o que seja mais favorável à sua lembrança na oração fúnebre e sobre a lápide tumular" (Freud, 1996: 300). Neste sujeito, representa-se, por fim, o herói.

Já a morte indiferente caracterizada por Barbosa é aquela banalizada pela violência: "a mídia, diante da violência, banaliza o corpo insepulto. A proliferação da morte violenta, fruto da guerra urbana e da desigualdade social, faz com que, para os meios de comunicação, neste caso, seja importante não a morte em si mesma, mas o espetáculo da brutalidade cotidiana” ( Barbosa, 2004: 2). Nos falecidos
Nos casos de vítimas da violência, 0 que está sendo representado não é a morte em si, e nem mesmo o morto, mas a tragédia, a criminalidade

anônimos, vítimas da violência banal, a sua re-significação, elaborada através da enunciação de sua morte no discurso midiático, está justamente na sua desqualificação enquanto sujeito a partir da naturalização da ocorrência - que pode transformá-lo, muitas vezes, na expressão numérica do fenômeno que lhe tirou a vida: a violência. Nos casos de vítimas da violência, o que está sendo representado não é a morte em si, e nem mesmo o morto, mas a tragédia, a criminalidade.

É válido reconhecer o quanto a morte enunciada permanece centrada "no outro", distante, que não se apresenta como ameaça concreta "a si". Nesta perspectiva, na impossibilidade de retirar a finitude e sua ameaça real do cotidiano, esta morte "dos outros" publicada representa uma lembrança constante, mas ao mesmo tempo distante. Uma forma de manter a morte existente - e isso não é opção, é fato - mas subtraída da ameaça de si ao ser projetada como perigo para "o outro". Esta convivência, de alguma maneira re-estabelece em "segurança” a relação entre homem e morte. Assim "o jornal atende a uma necessidade inconsciente, onde o cadáver 'ilustrado' morre 'por procuração' no lugar do leitor" (Angrimani, 1995: 56).

Uma outra construção de morte encontrada no discurso jornalístico é aquela que marca o aspecto de introjeção do poder da sociedade (especialmente do Estado) sobre o indivíduo, cuja coerção punitiva resguarda o controle da vida:

(...) a sociedade delega seu poder de carrasco a um de seus membros: este faz justiça em nome da lei, em nome do rei. Todos os outros homicídios são reprimidos por tabus, regras jurídicas, convenções ou ritos religiosos: cultua 
alguma os considera coisas insignificantes. Mas os homicídios praticados em nome do poder são diferentes: não são assassinatos, são "justiça” (Rodrigues, 1983: 107)

Volto, portanto, para a noção da morte como instância que auxilia na regulação da conexão social, pelo "sentido" de vida e participação que sugere aos indivíduos pertencentes a esta coletividade. Quando não é apresentada como irrupção, evento inesperado, acontecimento, a morte incorpora o sentido de regulação social pela coerção, inspirada como conseqüência àqueles que transgridem as regras. Este cenário estaria representado na morte "justa" daquele que promove a violência: o bandido. Nestes casos "admitimos a morte para estranhos e inimigos, destinando-os a ela tão prontamente e tão sem hesitação quanto ao homem primitivo" (Freud, 1996: 307). Assim, este poder do social sobre o indivíduo encontra seu espaço legitimado nas tramas do cotidiano, em que a vida é o preço pago pelo transgressor.

O controle do social sobre a atuação do sujeito se apresenta na inscrição dos papéis que sugerem a importância e a função de cada indivíduo na existência e manutenção do social. Isso implica, mais uma vez, concepção de "sentidos", expectativas do coletivo a serem cumpridas individualmente - o que, de certa forma, retira do sujeito a posse de sua vida: "O interesse do poder pela vida dos homens é também apropriação da morte deles. Poder algum admite a liberdade de suicídio. Vê-se nela uma afronta perigosa e intolerável" (Rodrigues, 1983: 107).

Presume-se compreender, portanto, a origem da condenação cívica, religiosa e moral do suicídio (e sua representação como tabu), como forma de manter distanciada a idéia de liberdade deste sujeito quanto ao fim de sua própria vida - é a sustentação do "todo", especialmente, que se preza. Daí, a decisão individual da morte, por ser inaceitável, é enquadrada nos campos da anormalidade (loucura ou possessão) para assumir significação que não revele as "falhas" do projeto social. Considerando a formulação do social pela atuação regulada dos sujeitos, a escolha individual pela interrupção da vida é concebida por muitos como a denúncia de uma crise coletiva.

Assim, segundo a perspectiva de que o sujeito existe em reciprocidade, em relação, torno à noção de interpelação causada pela inscrição da morte na narrativa jornalística. Em comparação àqueles sujeitos anteriormente citados (cujo falecimento noticiado se constrói na circunstância inusitada, no exercício da violência ou na proeminência do falecido), o suicida apresenta uma diferença fundamental: dentre todos, ele é o único que voluntariamente e conscientemente buscou (e agiu para) a sua própria morte. Percebese então como e por que a enunciação (ou não) da morte voluntária na narrativa jornalística revela o próprio caráter conflituoso do tema. As diferentes construções sobre a morte voluntária (sendo o silêncio também uma forma de tratar o tema) na narrativa jornalística explicitam este lugar tenso, e por vezes contraditório, que situa a relação entre morte, sujeito e coletividade. Para Dapieve (2007: 20) a postura reservada e discreta da imprensa ao tratar o suicídio assegura sua atuação como "instância social solidária ao tabu que a suplanta”.

\section{Geral e particular: sobre}

lógicas e formas de olhar o social

Considerando que este discurso sobre a 
morte se instaura no conflito e na complementaridade entre sujeito, sociedade e mídia, é importante conservar a cautela para que se possa extrair destes cenários aspectos importantes para revelar o social. Assim, deve-se considerar tudo o que precede esta elaboração, como os sentidos individuais e coletivos assumidos pela finitude, em suas regulações, ordenações e negociações, conforme contextos culturais e históricos específicos. Para visualizar esta narrativa jornalística também é preciso perceber as significações e re-ordenações de sentidos que se inscrevem na relação entre mídia e sociedade conforme especificidades que são subjacentes a cada grupo e contexto, em particular.

Se a morte revela este lugar de tensão na trama social, que se sustenta inclusive como tabu, é interessante dirigir a percepção para as narrativas jornalísticas, como discursos sobre e para a sociedade, que "criam e recriam práticas sociais discursivas que tanto desejam falar da sociedade como se constituir enquanto saber acerca desta mesma sociedade" (Resende, 2006: 161). Partindo desta noção sobre as narrativas, sem retirar a concepção do conflito existente na finitude, é interessante considerar o quanto o tema se inscreve de maneiras diferenciadas na pauta jornalística de nossa cultura.

Estes sentidos diversos que são atribuídos à morte como acontecimento jornalístico são parte do cenário complexo em que os atores sociais interseccionam referências diversas: culturais, históricas, subjetivas, individuais e coletivas. Sem dúvida, falase de um espaço em que a experiência viva das relações, onde se formulam tais narrativas, tem atuação expressiva da comunicação. Para mortes diferentes, observamos

\section{Sentidos diversos atribuídos à morte como acontecimento jornalístico são parte do cenário complexo em que os atores sociais interseccionam referências culturais, históricas, subjetivas, individuais e coletivas}

sujeitos e contextos distintos. Estas significações, por sua vez, interpelam os atores do processo comunicacional de formas variadas. Esta consideração exige perceber a comunicação como espelho da pluralidade que alimenta os processos sociais. "Essa pluralidade e diversidade de lógicas seguindo práticas específicas remetem a novas interpretações do espaço e do tempo presentes também na comunicação" (Sousa, 1994: 29).

A percepção destas lógicas específicas, como possibilidades explicativas da vida social, permite a abertura para novos olhares e significados para o tempo social, em que a articulação entre comunicação e sociedade se apresenta como esfera rica de observação. Assim, a compreensão dos sentidos construídos a partir da enunciação da morte no discurso jornalístico possibilita a noção do quanto estas narrativas afloraram sentidos, bem como re-elaboram novas significações para a relação tão fundamental que se institui entre homem, cultura e morte. Por isto, a observação da estruturação deste discurso jornalístico sobre a morte a partir de seu processo de construção de significados, na própria enunciação, é preponderante. Poderá se ver mais do exercício e da participação do jornalismo como também do próprio homem: "A mídia, portanto, explora aspectos fundamentais de como o homem contemporâneo coloca-se diante da morte e através de encenações de sentido que produz pode-se reconstruir cenários de significações do mundo contemporâneo" (Barbosa, 2004: 14).

Ora, se entendemos a mediação como espaço em que se dão a estruturação e a organização da percepção da realidade, admite-se, portanto, o papel dos media operando ativamente no processo de construção desta realidade percebida. Desta maneira, no caso da morte, a observação deste palco se dá na percepção de relatos que partem sempre $e$ 
necessariamente de representações de algo que, para além do fato narrado, trazem em seu cerne uma relação estruturante do sujeito e da sociedade. Assim, é interessante tentar perceber de que maneira os sentidos construídos a partir da enunciação jornalística se orientam e interpretam os sentidos de pertença, de vida e de morte, fundados pela certeza da finitude. Como significações que se formulam sobre e para a sociedade, são narrativas que, pela sua elaboração e reinserção nas tramas da cultura, permitem observar, em movimento, em existência viva, a relação recíproca, e por isso, rica, entre os processos sociais e a comunicação.

\section{Sobre a autora}

Milena Oliveira-Cruz, Mestre em Ciências Sociais (UFRN), Professora da Universidade Federal do Piauí (UFPI).

email: milena.freire@terra.com.br

\section{Referências}

ANGRIMANI, Danilo. Espreme que sai sangue: um estudo do sensacionalismo na imprensa. São Paulo: Summus, 1995.

ARIÈS, Philippe. A história da morte no Ocidente. Rio de Janeiro: Ediouro, 2003.

BARBOSA, Marialva. A morte imaginada: In Encontro Anual da Associação Nacional dos Programas de Pós-Graduação Em Comunicação/ Compós, 13., 2004, São Bernardo do Campo.

BERGER, Perter L.; LUCKMANN, Thomas. A construção social da realidade: tratado de sociologia do conhecimento. Petrópolis: Vozes, 1985.

CAMUS, Albert. $O$ mito de Sísifo: ensaio sobre o absurdo. Lisboa: Edições Livros do Brasil, s/d.

CASTELLS, Manuel. A Sociedade em rede. São Paulo: Paz e Terra, 1999.

DAPIEVE, Arthur. Moreu na contramão: o suicídio como notícia. Rio de Janeiro: Jorge Zahar, 2007. DASTUR, Françoise. A morte: ensaio sobre a finitude. Rio de Janeiro: DIFEL, 2002.

ELIAS, Norbert. A solidão dos moribundos, seguido de, Envelhecer e morrer. Rio de Janeiro: Jorge Zahar, 2001.

FREUD, Sigmund. Reflexões para os tempos de guerra e morte: In Obras Psicológicas Completas de Sigmund Freud. Vol. XIV. Rio de Janeiro: Imago, 1996. p. 282-312.

GEETZ, Clifford. A interpretação das culturas. Rio de Janeiro: LTC, 1989.

GIDDENS, Anthony. Modernidade e identidade. Rio de Janeiro: Jorge Zahar, 2002.

KOVÁCS, Maria Júlia. Morte e desenvolvimento humano. São Paulo: Casa do Psicólogo, 1992.

MOLOTCH, Harvey; LESTER, Marilyn. As notícias como procedimento intencional: acerca do uso estratégico de acontecimentos de rotina, acidentes e escândalos: In TRAQUINA, Nelson (org.). Jornalismo: questões, teorias e 'estórias'. Lisboa: Vega, 1993.

MORIN, Edgar. O homem e a morte. Rio de Janeiro: Imago, 1997.

RESENDE, Fernando. Jornalismo e enunciação: perspectivas para um narrador-jornalista. In: LEMOS, André; BERGER, Christa; BARBOSA, Marialva (org.). Narrativas midiáticas contemporâneas. Porto Alegre: Sulina, 2006.

RODRIGUES, Adriano Duarte. $O$ acontecimento. In: TRAQUINA, Nelson (org.). Jornalismo: questões, teorias e 'estórias'. Lisboa: Vega, 1993. RODRIGUES, José Carlos. Tabu da morte. Rio de Janeiro: Achiamé, 1983.

SOUSA, Mauro W. Recepção e comunicação: a busca do sujeito: In (org). Sujeito, o lado oculto do receptor. São Paulo: Brasiliense, 1994. p. 13-38.

Recebido em 3 de março de 2008 Aprovado em 28 de abril de 2008 